\title{
CSF Shunt Infections: A Fifteen-Year Experience with Emphasis on Management and Outcome
}

\author{
Isabelle Morissette, Marie Gourdeau and Jacques Francoeur
}

\begin{abstract}
A retrospective study of patients with cerebrospinal fluid shunt infections was undertaken from 1975 to 1989 in a university hospital. The data were analyzed with emphasis on the choice of treatment and outcome. There were 44 infectious episodes in 38 patients for an overall rate of $2.6 \%$, including 30 ventriculoperitoneal, 11 ventriculoatrial and 3 lumboperitoneal shunts. The most frequently isolated pathogens were staphylococci in $61 \%$ of the cases followed by gram-negative bacilli in $25 \%$. Different modalities of treatment were used: support (2), intravenous antibiotics alone (6), intravenous antibiotics and shunt revision (3), intravenous antibiotics and shunt removal with or without prior externalization of the distal end $(33: 13+20)$. The cure rate was $94 \%(31 / 33)$ with this last modality of treatment. Only 3 patients received intraventricular antibiotics. All deaths occurred in patients treated with support only (2) or with antibiotics alone (1). Four of the six recurrent episodes occurred in patients treated with antibiotics alone (2) or with a shunt revision (2). We conclude that carefully chosen intravenous antibiotics combined with shunt removal preceded or not by externalization of the distal end as an alternative therapy to repeated ventricular taps or insertion of an external ventricular drainage device is an appropriate therapy.
\end{abstract}

\begin{abstract}
RÉSUMÉ: Infections de dérivations ventriculaires: une expérience de quinze ans - le traitement et son issue. Une étude rétrospective des infections de dérivations ventriculaires de 1975 à 1989 dans un hôpital universitaire nous a permis d'identifier 44 épisodes infectieux chez 38 patients, incluant 30 infections de dérivations ventriculo-péritonéales, 11 ventriculo-cardiaques et 3 lombo-péritonéales. L'incidence globale d'infection a été de $2.6 \%$. Les pathogènes les plus fréquemment rencontrés ont été les staphylocoques (61\%) et les bâtonnets Gramnégatif (25\%). Les différentes modalités de traitement utilisées ont été: support (2), antibiothérapie intraveineuse seule (6), antibiothérapie et révision de la dérivation (3), antibiothérapie et exérèse de la dérivation associée ou non à une extériorisation préalable de l'extrémité distale $(33: 13+20)$. Ce dernier traitement a remporté un succès de $94 \%(31 / 33)$. Seulement 3 patients ont reçu des injections intraventriculaires d'antibiotiques. Tous les décès ont eu lieu chez des patients $n$ 'ayant reçu aucun traitement spécifique (2) ou une antibiothérapie seule (1). Des 6 récidives, 4 ont eu lieu chez des patients traités avec une antibiothérapie seule (2) ou associée à une revision sans exérèse (2). Une antibiothérapie intraveineuse adéquate associée à l'exérèse de la dérivation, précédée ou non de l'extériorisation de son extrémité distale à la place de l'insertion d'un drain ventriculaire externe ou de ponctions ventriculaires répétées constituent une thérapie adéquate.
\end{abstract}

Can. J. Neurol. Sci. 1993; 20: 118-122

Since 1970, ventriculoperitoneal (VP) shunts have been promoted for treatment of patients with hydrocephalus much more frequently than ventriculoatrial (VA) shunts. The infection rate of CSF shunt procedures fluctuate from 2 to $31 \%$, depending on the centre, the risk factors, and the denominator used. ${ }^{1-6}$

Various methods of treatment have been recommended. The most common consists first of intravenous and intraventricular antibiotics, secondly complete removal of the shunt combined with the insertion through a burr hole of an external ventricular drainage device (EVD) to control intraventricular pressure and finally, reinsertion of a contralateral shunt after infection has been controlled. ${ }^{6-8}$ McLaurin and Frame ${ }^{9}$ have suggested a variation in the treatment of VP shunt infection, which involves the externalization of the distal (peritoneal) catheter with closedsystem drainage, the administration of systemic and intraventricular antibiotics, and finally a new catheter inserted into the peritoneal cavity and attached to the existing distal catheter high in the thoracic area. The externalization of the distal end will control intraventricular pressure and will exclude the need for an EVD through a burr hole or repeated ventricular taps. In McLaurin's study, 10 of 11 patients were cured of their infection with this method of management.

From the Clinical Microbiology (I.M., M.G.) and Neurosurgery (J.F.) Services, Hôpital de l'Enfant-Jésus, Université Laval, Québec

Received December 17, 1991. Accepted in final form December 22, 1992

Reprint requests to: Dr. Marie Gourdeau, Laboratoire de Microbiologie, Hôpital de l'Enfant-Jésus, 1401 18e rue, Québec, Québec, Canada Gı J 124 
At our centre, the standard treatment of VP shunt infection in recent years includes intravenous (not intraventricular) antibiotics, externalization of the distal end of the shunt in the first days, and removal of the old shunt with total replacement with a contralateral shunt, 5 to 7 days later when the infection is usually under control. We present our experience with this therapy and analyze the incidence, the bacteriological features, and the outcome of the infections.

\section{Materials and) Methods}

The medical records of all CSF shunt infections from January 1975 to December 1989 were retrospectively reviewed in a tertiary-care hospital. The criteria retained for CSF shunt infection were: isolation of a bacterial pathogen in the CSF (obtained either by lumbar, ventricular, or reservoir puncture), valve culture, or blood (VA shunt only) and/or CSF pleocytosis (more than 10 leukocytes per $\mathrm{mm}^{3}$ ) in a patient with suggestive clinical manifestations such as fever, neurologic and abdominal symptoms and/or signs and evidence of shunt malfunction. Recurrent infection was defined by the same criteria as in the initial episode; reinfection consisted of an episode with different bacteria isolated from the culture and relapse occurred if the same bacteria were isolated as in the previous episode.

Different treatment options of the infection were chosen, varying from support alone to medical treatment (intravenous antibiotics) with or without surgical intervention. Shunt replacement was defined as an operative procedure in which all components of the shunt, tubing, and reservoir were replaced. Shunt revision was defined as the exploration of a shunt with replacement of some parts. The EVD consisted of insertion of an intraventricular drainage system through a burr hole after removal of the entire shunt. Externalization of the distal catheter with a closed system drainage was noted if done. All neurosurgeons used the same technique and the same type of shunt: Raimondi (VP and LP) and Pudenz (VA). Fischer's exact test and the unpaired T-test were used for the statistical evaluation of the data compared.

\section{RESULTS}

We identified 44 shunt infections in 38 patients ( 5 relapses, 1 reinfection) during the 15-year period: these involved $30 \mathrm{VP}$ shunts, 11 VA shunts, and 3 LP shunts. In all, 21 males and 17 females, aged between twenty-six days and fifty-nine years (median: 2 years) were involved. The median age in the VP group was 1 year (mean: $6.25 \pm 12.5$ ). There was one neonate (0-1 month of age) and 12 infants ( 1 month to 1 year). The patients in the VA group were significantly older (median: 18 years; mean: $19.48 \pm 17.1$ ). Only one neonate and one infant were included in that group. The etiology of the hydrocephalus is listed in Table 1.

A total of 1,061 procedures have been performed in the last 9 years (the data are not available from January 1975 to March 1980), including 600 insertions ( $175 \mathrm{VA} ; 320 \mathrm{VP} ; 105$ others), 382 revisions or replacements, and 79 removals excluding ventriculostomy. Twenty-eight shunt infections occurred in this period. The infection rate by procedure was $2.6 \%$, and the annual incidence rate of infection ranged from $0.8 \%$ to $3.8 \%$, the highest incidence occurring in 1983 and progressively decreasing since then to an incidence of $1.9 \%$ in 1989 . The clinical presen- tation involved most frequently was fever, irritability, and mild to severe signs of increased intracranial pressure. Three patients $(7.3 \%)$ had wound infections, all involving staphylococci. Two infections involved a distant focus of infection: one patient (LP) had appendicitis and peritonitis, with Pseludomonas aeruginosa as the causative pathogen. One case (VP) had positive urine and CSF cultures with Escherichia coli.

The delay between shunt surgery and clinically apparent shunt infection was less than 3 months from the last surgical procedure in $52 \%(23 / 44)$ of all shum infections. All 4 Staphylococcus aureus infections occurred within the first 3 months. Only 12 infections (27\%) became clinically apparent one year after the last surgical procedure, including 7 of the 9 episodes of infections associated with Gram-negative bacilli.

Table 2 shows the bacterial etiology of the 44 infections according to the type of shunt; 6 infectious episodes involve more than one organism, most commonly viridans streptococci. Gram-negative bacilli, and anaerobes. Eleven Gram-negative bacilli were involved in 9 episodes (VP: 7/44, LP: 2/44). None of these infections was associated to VA shunt and none occurred in neonates. All these patients, except for one adult, were children aged between 1 and 11 years.

The bacteriological features of CSF shunt infection are presented in Table 3. CSF culture was positive in $85 \%(34 / 40)$ of the cases and in the four instances when it was not done ( 3 VA,

Table 1. Etiology of Hydrocephalus

\begin{tabular}{lcc}
\hline \hline Etiology & No. of Cases & Percentage \\
\hline Myelomeningocele & 12 & 31.6 \\
Tumor or cyst & 7 & 18.4 \\
Aqueduct stenosis & 4 & 10.5 \\
Post-meningitic & 3 & 7.9 \\
Post-traumatic & 2 & 5.3 \\
Others & 10 & 26.3 \\
$\quad$ Total & 38 & 100.0 \\
\hline
\end{tabular}

Table 2. Infecting Organisms According to the Type of Shunt'

\begin{tabular}{lll}
\hline Pathogen & VP (30) & Vype of Shunt \\
(11) & LP (3)
\end{tabular}

Staphylococcus coagulase negative

Staphylococcus coagulase positive

Micrococcus

Gram-negative bacilli

Streptococcus $s p^{3}$

Anaerobes

Total

$\begin{array}{cccc}22 & 13 & 9 & 0 \\ 5 & 4 & 1 & 0 \\ 2 & 2 & 0 & 0 \\ 11^{4} & 9 & 0 & 2 \\ 7 & 4 & 2 & 1 \\ 4 & 3 & 1 & 0 \\ 51^{5} & 35^{5} & 13^{5} & 3\end{array}$

' Negative CSF, blood and valve cultures but pleocytosis and clinical manifestations (3)

${ }^{2} \mathrm{~S}$. aureus (4), S. intermedius (1)

${ }^{3} \mathrm{~S}$. viridans (5), S. pyogenes (1), S. pneumoniae (1)

${ }^{4}$ Escherichia coli (3), Klebsiella oxyloca (2), Pseudomonas aeruginosa (3), Haemophilus influenzae (I), Acinetobacter calcoaceticus (I), Proteus vulgaris (1)

5 Six infections involved more than one organism: VP (4), VA (2) 
I LP), either blood culture (3) and/or the valve (3) was positive. Two cases (I VP, I LP) had positive cultures for the valve only, CSF and blood cultures being negative or not available.

The results of the first course of therapy for patients with VP and VA shunt infections are illustrated in Tables 4 and 5 respectively. Three deaths (Table 4) occurred in our series: one patient treated with intravenous antibiotics alone (day 3 of treatment) and the 2 patients treated with support only because of the underlying neurological deficit. The six infectious episodes managed with antibiotics alone (4 VP; $2 \mathrm{VA}$ ) were all treated before 1985 and involved staphylococci (S. epidermidis (4), $S$. imermedius (1), negative culture (1)). Two patients relapsed despite appropriate antibiotherapy, 28 and 120 days later. Three patients had antibiotics and shunt revision, a procedure which was effective in only one of the cases. These infections were caused by $S$. epidermidis (2) and Micrococcus sp (1).

The two relapses involved VP shunts although both were treated with a penicillin and an aminoglycosid for 20 days and revision at day 1 and 19 respectively. The last case also had an

Table 3. Bacteriological Features of CSF Shunt Infection

\begin{tabular}{llll}
\hline \hline & \multicolumn{3}{c}{ Type of Shunt (Total Number) } \\
Laboratory Results & VP(30) & VA (11) & LP (3) \\
\hline $\begin{array}{l}\text { No. (\%) of } \\
\quad \text { Positive blood cultures }\end{array}$ & $2 / 21(10 \%)$ & $9 / 10(90 \%)$ & $1 / 1(100 \%)$ \\
$\begin{array}{l}\text { No. (\%) of } \\
\quad \text { Positive CSF cultures }\end{array}$ & $26 / 30(87 \%)$ & $6 / 8(75 \%)$ & $2 / 2(100 \%)$ \\
$\begin{array}{l}\text { No. (\%) of } \\
\text { Positive gram-stained CSF }\end{array}$ & $11 / 30(37 \%)$ & $4 / 8(50 \%)$ & $1 / 2(50 \%)$ \\
\hline
\end{tabular}

'The three peritoneal shunt infections with positive blood cultures (VP:

2, LP: 1) also had a positive LCR culture. externalization of the distal end 8 days before the revision.

The majority of our patients (22/30 VP shunts; $8 / 11$ VA shunts; $3 / 3$ LP shunts) were treated with antibiotics and removal of the shunt, delayed more than 48 hours in 30/33. All Gramnegative infections (2 LP, $7 \mathrm{VP}$ ) were included in this group. Among the 22 VP shunt infections where the shunt was removed, the treatment further involved 2 different surgical procedures before replacement by a new shunt: a) externalization of the distal end of the infected shunt $(12)$; b) removal of the infected shunt and insertion of an EVD through a burr hole (6). In one case, the replacement was done at the same time of the removal and in 3 instances, no replacement was done. The rate of cure obtained was $95 \%(21 / 22)$. The clinical characteristics and outcome of the treatment of these $18 \mathrm{VP}$ infectious episodes along with one LP case with respect to these 2 different surgical procedures are reported in Table 6.

The 3 LP shunt infectious episodes were all treated with antibiotics and delayed removal of the shunt. There was one case due to $P$. aeruginosa which relapsed, although ceftazidime and tobramycin administered for 24 days plus 2 doses of intraventricular gentamycin and externalization (day 3 ) followed by total replacement of the shunt (day 16) had been performed during the first episode.

There were only 3 cases treated with intraventricular antibiotics: the LP case infected with $P$. aeruginosa mentioned above (first episode and relapse) and the episode of relapsed infection with $E$. coli.

\section{Discussion}

During the 15-year period, the infection rate of CSF shunts calculated by operative procedure never exceeded $3.3 \%$. The fact that the same 3 neurosurgeons performed all the procedures using a standardized technique may have contributed to this low

Table 4. Management and Outcome of 30 Episodes of VP Shunt Infections

\begin{tabular}{lcccc}
\hline \hline Type of Management & No. of Episodes & No. $(\%)$ with Cure & No. $(\%)$ with Recurrence & No. (\%) with Death \\
\hline Support & 2 & 0 & 0 & $2(100)$ \\
Antibiotics alone & 4 & $1(25)$ & $2(50)$ & $1(25)$ \\
Antibiotics and shunt revision & 2 & 0 & $2(100)$ & 0 \\
Antibiotics and shunt removal 1.2 .3 & 22 & $21(95)$ & $1^{4}(5)$ & 0 \\
$\quad$ Total & 30 & $22(73.3)$ & $5(16.7)$ & $3(10)$ \\
\hline
\end{tabular}

1 Immediate (2), delayed more than 48 hours (20), delay varied from 4 to 26 days (mean: 13.8)

${ }^{2}$ Externalization of the peritoneal portion (12); delay varied from 0 to 12 days (mean: 3.6 )

${ }^{3}$ Antibiotics administered 7 to 39 days (mean: 32 )

${ }^{4}$ Escherichia coli

Table 5. Management and Outcome of VA Shunt Infections (11)

\begin{tabular}{lcccc}
\hline \hline Type of Management & No. of Episodes & No. (\%) with Cure & No. (\%) with Recurrence & No. (\%) with Death \\
\hline Support & 0 & 0 & 0 & 0 \\
Antibiotics alone & 2 & $2(100)$ & 0 & 0 \\
Antibiotics and shunt revision & 1 & $1(100)$ & 0 & 0 \\
Antibiotics and shunt removal 1.2 & 8 & $8(100)$ & 0 & 0 \\
$\quad$ Total & 11 & $11(100)$ & 0 & 0 \\
\hline
\end{tabular}

1 Immediate (1), delayed more than 48 hours (7), delay varied from 5 to 26 days (mean: 11.6 )

${ }^{2}$ Antibiotics administered 8 to 39 days (mean: 23.2 ) 
Table 6. Clinical Characteristics of VP and LP Shunt Infections Treated with Shunt Removal (25) ${ }^{1}$ and Externalization ${ }^{2}$ or EVD ${ }^{3}$

\begin{tabular}{|c|c|c|c|}
\hline & $\mathrm{XT}^{2}(13)$ & $\operatorname{EVD}^{3}(6)$ & $\mathbf{P}^{4}$ \\
\hline Age, yr - mean & 7.8 & 2 & NS \\
\hline - median & 0.75 & 2 & NS \\
\hline $\operatorname{Sex} M / F$ & $6 / 7$ & $4 / 2$ & NS \\
\hline Etiology of Hydrocephalus & & & NS \\
\hline Myelomeningocele & 6 & 1 & \\
\hline Tumor or cyst & 1 & 2 & \\
\hline Aqueduct stenosis & 2 & 0 & \\
\hline Post meningitic & 1 & 1 & \\
\hline Other & 3 & 2 & \\
\hline Antecedent of shunt revision or removal & 5 & 3 & NS \\
\hline Antibioprophylaxis & 3 & 0 & NS \\
\hline Etiology of infection 5 & & & NS \\
\hline Gram-positive cocci & 8 & 2 & \\
\hline Gram-negative bacilli & 5 & 2 & \\
\hline Incubation, months & & & NS \\
\hline $0-3$ & 7 & 2 & \\
\hline $0-12$ & 3 & 4 & \\
\hline$>12$ & 3 & 0 & \\
\hline Mean length of stay of EVD ${ }^{3}$ or EXT' (days) & s) 14 & 8 & NS \\
\hline Treatment outcome & & & NS \\
\hline Cure & 12 & 5 & \\
\hline Relapse & 1 & 1 & \\
\hline
\end{tabular}

1 Immediate replacement (VP: 1, LP: 2), no replacement (VP: 3)

2 Externalization of the distal end of the infected shunt before removal and replacement (VP: 12, LP: I)

3 Insertion of an extraventricular device through a burr hole after removal of the old shunt (VP: 6, LP: 0)

4 Unpaired T-test (mean) and Fischer's exact test (proportion)

5 Negative cultures (2)

infection rate. Because of the retrospective design of our study, we were unable to identify risk factors of infection. Prophylactic antibiotics were not routinely used during this period (8/44) and cannot account for the observed infection rate. Because of a trend suggesting a need for prophylaxis in smaller studies and of the catastrophic consequences if an infection occurs, the administration of perioperative antibiotics is now a current practice in our hospital even if this matter is still controversial. ${ }^{6-8} .10-12$

As in previously reported series, staphylococci were involved

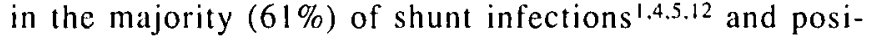
tive-coagulase staphylococci more frequently associated to wound infections $s^{1,2,4.12}$ and to acute onset. ${ }^{1.2 .5}$ In contrast, most Gram-negative infections had a delayed onset (7/9 more than one year after surgery), suggesting inoculation some time after the surgery. Bowel perforation is a predisposing event discussed by some authors, ${ }^{1.7 .12-15}$ particularly in the setting of a mixed infection involving anaerobes and Gram-negative enteric bacilli. An infection could also result from the ascent of bacteria from the gastro-intestinal tract without overt abdominal infection or in the selting of an intercurrent site of infection. ${ }^{2-4}$ In this series, one case (LP) was associated with appendicitis and peritonitis, and another one (VP) with an urinary tract infection.

Surgical removal of the shunt apparatus, insertion of an EVD through a burr hole in combination with systemic and intraven- tricular antibiotics followed by total replacement is the therapy with the highest success in the literature. ${ }^{5-7.12}$ The preferred therapy in our hospital consists of systemic antibiotics only, combined with surgical removal and contralateral replacement of the shunt. Thirty-three infections (Tables 4,5 ) were managed with this therapy (VP: 22, VA: 8, LP: 3 ) and the rate of cure was $94 \%$.

There is a potential risk of superinfection from the EVD 6.7 .12 .16 through a burr hole and when placed in a young child who cannot cooperate, the danger of disconnecting the system is always present. Repeated ventricular taps do not control intraventricular pressure as constantly, these need a member of the staff available 24 hours a day and are much more traumatizing for the patient. Externalization of the distal portion of the catheter constantly controls the intraventricular pressure and avoids most of the inconveniences associated with EVD through a burr hole or repeated taps. In addition, this procedure can prevent the occurrence of a localized peritoneal reaction (pseudocyst or abscess) and secondary obstruction. In this series (Table 6), 13 infections (VP: 12, LP: 1) were treated with an externalization of the distal catheter before replacement and in 6 episodes (VP: 6) an EVD was inserted through a burr hole instead. There was no statistical difference in the clinical characteristics and outcome of treatment between the two groups. There was one relapse in each group and both involved Gramnegative bacilli. Externalization of the catheter is more practical than inserting an EVD through a burr hole and in our experience, the results obtained have been as satisfactory.

By administrating systemic antibiotics 7 to 10 days after replacement, the patient's length of stay in the hospital ranged between 18 and 21 days, which is very acceptable. Cure of the infections was achieved without use of intraventricular antibiotics. There is no unanimity concerning the role of intraventricular antibiotics in the treatment of CSF shunts due to a lack of pharmacokinetic data and of controlled studies in this situation. Excessively high intraventricular antimicrobial levels are associated with neurotoxicity. ${ }^{6-8}$ Considering the views expressed in the literature and our experience, we prefer to limit the administration of intraventricular antibiotics to multiresistant organisms when aminoglycosids are essential, when surgery is contra-indicated, or when there is a recurrent episode.

\section{Conclusion}

This retrospective analysis of CSF shunt infections shows the validity of the following management: in the first days, we perform an externalization of the shunt and analyse daily CSF cytology and culture. Five to 7 days later, when the infection is under control, a complete removal of the shunt and contralateral replacement is performed. Systemic antibiotics are administered for at least seven days after the shunt replacement; however we limit the administration of intraventricular antibiotics to the few situations listed above.

\section{REFERENCES}

1. Odio C, McCracken H, Nelson JD. CSF shunt infections in pediatrics: a seven year experience. Am J Dis Child 1984; 138: 11031108.

2. Renier D, Lacombe J, Pierre-Kahn A, et al. Factors causing acute shunt infection: computer analysis of 1174 operations. J Neurosurg 1984; 61: 1072-1078. 
3. Quigley MR, Reigel DH, Kortyna R. Cerebrospinal fluid infections: report of 41 cases and a critical review of the literature. Pediatr Neurosci 1989; 15:111-120.

4. Spanu G, Karussos G, Adinolfi D, el al. An analysis of cerebrospinal fluid shunt infections in adults. A clinical experience of twelve years. Acta Neurochirurgica 1986; 80: 79-82.

5. Schoenbaum SC, Gardner P, Shillito J. Infections of cerebrospinal fluid shunts: epidemiology, clinical manifestations and therapy. $J$ Infect Dis 1975; 131: 543-552.

6. Bisno Alan L. Infections of central nervous system shunts. In: Bisno AL, Waldvogel FA, eds. Infections Associated with Indwelling Medical Devices. Washington: ASM 1989; 93-109.

7. James HE. Infections associated with cerebrospinal fluid prosthetic devices. In: Sugarman B. Young EJ, eds. Infections Associated with Prosthetic Devices. Boca Raton: CRC Press Inc 1984; 2341.

8. Venes JL. Infections of CSF shunt and intracranial pressure monitoring devices. In: Grant $\mathrm{O}$ Westenfelder, ed. Infections of Prosthetic Devices, Infectious Disease Clinics of North America. Philadelphia: WB Saunders Co 1989; 3: 289-299.
9. McLaurin RL, Frame PT. Treatment of infections of cerebrospinal fluid shunts. Rev Infect Dis 1987; 9: 595-603.

10. Shapiro M. Prophylaxis in otolaryngologic surgery and neurosurgery: a critical review. Rev Infect Dis 1991; 13 (Suppl 10): S858-S868.

11. Haines SJ. Antibiotic prophylaxis in neurosurgery. The controlled trials. Neurosurg Clin N Am 1992; 3 (2): 355-358.

12. Walters BC. Cerebrospinal fluid shunt infection. Neurosurg Clin $\mathrm{N}$ Am 1992; 3 (2): $387-401$.

13. Brook I, Johnson N, Overturf GD, et al. Mixed bacterial meningitis: a complication of ventriculo- and lumboperitoneal shunts; Report of two cases. J Neurosurg 1977; 47: 961-964.

14. Rekate HL, Yonas $\mathrm{H}$, White RF, et al. The acute abdomen in patients with ventriculoperitoneal shunts. Surg Neurol 1979; 11: 442-445.

15. Rush DS, Walsh JW, et al. Ventricular sepsis and abdominally related complications in children with cerebrospinal fluid shunts. Surgery 1985; 97: 420-427.

16. Mayhall $\mathrm{CG}$, Archer $\mathrm{NH}$, et al. Ventriculostomy-related infections N Engl J Med 1984; 310: 553-559. 